\title{
Monitoring of Minimal Residual Disease (MRD) in Chronic Myeloid Leukemia: Recent Advances
}

This article was published in the following Dove Press journal:

Cancer Management and Research

\section{Cosimo Cumbo $\mathbb{D}^{*}$ \\ Luisa Anelli $\mathbb{1}^{*}$ \\ Giorgina Specchia \\ Francesco Albano (D)}

Department of Emergency and Organ Transplantation (D.E.T.O.), Hematology Section, University of Bari, Bari 70124, Italy

*These authors contributed equally to this work
Correspondence: Francesco Albano Department of Emergency and Organ Transplantation (D.E.T.O.), Hematology

Section, University of Bari, P.zza

G. Cesare, II, Bari 70124, Italy

Tel +39 080-547803I

Fax $+39080-5508369$

Email francesco.albano@uniba.it

\begin{abstract}
Chronic myeloid leukemia (CML) is a myeloproliferative neoplasm caused by the $B C R-A B L 1$ fusion gene generation as a consequence of the $\mathrm{t}(9 ; 22)(\mathrm{q} 34 ; \mathrm{q} 11)$ rearrangement. The identification of the $B C R-A B L 1$ transcript was of critical importance for both CML diagnosis and minimal residual disease (MRD) monitoring. In this review, we report the recent advances in the CML MRD monitoring based on RNA, DNA and protein analysis. The detection of the $B C R-A B L 1$ transcript by the quantitative reverse-transcriptase polymerase chain reaction is the gold standard method, but other systems based on digital PCR or on GeneXpert technology have been developed. In the last years, DNA-based assays showed high sensitivity and specificity, and flow cytometric approaches for the detection of the $\mathrm{BCR}-\mathrm{ABL} 1$ fusion protein have also been tested. Recently, new MRD monitoring systems based on the detection of molecular markers other than the $B C R-A B L 1$ fusion were proposed. These approaches, such as the identification of CD26+ leukemic stem cells, microRNAs and mitochondrial DNA mutations, just remain preliminary and need to be implemented. In the precision medicine era, the constant improvement of the CML MRD monitoring practice could allow clinicians to choose the best therapeutic algorithm and a more accurate selection of CML patients eligible for the tyrosine kinase inhibitors discontinuation.

Keywords: chronic myeloid leukemia, minimal residual disease, MRD monitoring
\end{abstract}

\section{Introduction}

Chronic myeloid leukemia (CML) is a clonal myeloproliferative disorder driven by the chimeric BCR-ABL1 oncoprotein, resulting from a $t(9 ; 22)(\mathrm{q} 34 ; \mathrm{q} 11)$ balanced reciprocal translocation. The rearrangement produces the Philadelphia $(\mathrm{Ph})$ chromosome where the $B C R-A B L 1$ oncogene is generated; its chimeric transcript is the marker of the disease. ${ }^{1,2}$ Tyrosine kinase inhibitors (TKIs) therapy targets $B C R-A B L 1$ positive cells and induces hematologic and molecular remission in $80-90 \%$ of CML patients, with a survival rate comparable to that of age-matched

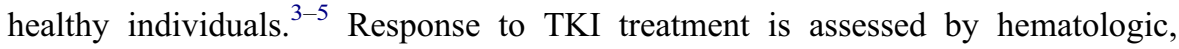
cytogenetic, and molecular testing performed at specific time-points during followup. Detection of the $B C R-A B L 1$ transcript level by quantitative reverse-transcriptase polymerase chain reaction (RQ-PCR) is the gold standard method for monitoring CML minimal residual disease (MRD) and the optimal CML patient management. ${ }^{6}$ In fact, standardized and regular MRD monitoring in CML patients is essential for defining the response to treatment and choosing the best therapeutic strategy (as well as providing prognostic information) and also for selecting patients in sustained deep molecular response who are eligible for TKI discontinuation. ${ }^{7}$ This gains relevance in the era of targeted therapy, where the introduction of MRD 
monitoring has profoundly transformed patients management. ${ }^{8}$ Efficient methods for disease monitoring should guarantee fast, inexpensive and sensitive disease detection. In fact, even if in the last two decades the standardization of CML monitoring has remained one of the most laborious procedures, the efficacy of different new approaches has recently been tested. The main strategies developed in the last years, are based on $B C R-A B L 1$ chimeric gene or transcript or protein detection, although some alternative strategies have been made (Figure 1). In this review we summarize the recent advances in the CML MRD monitoring, considering the advantages and disadvantages of each approach and focusing on future perspectives.

\section{BCR-ABLI-Dependent MRD Monitoring \\ RNA-Based Approaches \\ RQ-PCR Monitoring and Standardization of the Experimental Procedure}

CML molecular monitoring by RQ-PCR is based on total RNA extraction from peripheral blood (PB) or bone marrow (BM) cells, reverse-transcription of RNA into cDNA, and quantitative co-amplification of the $B C R-A B L 1$ transcript and of an internal housekeeping gene. Molecular monitoring in CML should be performed according to the established Europe Against Cancer criteria, defining specific primer/probe systems for both $B C R-A B L 1$ and $A B L 1$ genes. ${ }^{9}$ As many experimental steps and technical details can cause variability and heterogeneity in RQ-PCR analysis, the EUropean Treatment Outcome Study (EUTOS) program in Europe and the LabNet network in Italy, promoted the standardization of RQ-PCR procedures and establishment of the expression of $B C R-A B L 1$ transcript level as "international scale (IS)" $\cdot{ }^{10-13}$ The baseline $B C R-A B L 1$ RNA level (100\% IS) was defined as the median $B C R-A B L 1$ transcript level to reference gene ratio in 30 newly diagnosed CML patients in the IRIS study. ${ }^{14,15}$ The most commonly used reference genes are $A B L 1, G U S B$ or $B C R$; $A B L 1$ is used by most laboratories worldwide, GUSB is used by some European laboratories, whereas $B C R$ is employed as reference gene in Australasia and some US laboratories. ${ }^{12,14,16}$ In the IRIS study, the second $B C R-A B L 1$ IS level corresponds to a 1000fold $(3-\log )$ reduction in the $B C R-A B L 1$ transcript level compared to the IRIS baseline, defining a major molecular response (MMR). There are two possible ways of calculating the IS: according to the Conversion Factor (CF) or using the $B C R-A B L 1$ reference standard method. At the time of the IRIS trial, the Adelaide laboratory served as central reference laboratory, and sample exchange was performed with 38 different international laboratories to attribute the specific $\mathrm{CF}$ expressing the $B C R-A B L 1$ transcript level according to the IS. ${ }^{17}$ To determine the $C F$, each set of data generated by a specific laboratory was compared with that obtained by the reference laboratory, using the statistical comparison procedure of Bland and Altman. ${ }^{17}$ In this method the $B C R-A B L 1$ IS value is expressed as follows: [(sum of $B C R-A B L 1$ copies $) /($ sum of reference gene copies $)] \times \mathrm{CF} \times 100$. $^{13,17}$ However, this system is time-consuming and laborious due to the need for many samples exchange between different laboratories. The second method for standardization to the IS, that will probably become the main system in the future, is the use of secondary $B C R-A B L 1$ reference standard samples, now commercially available although they are not yet FDA-approved. ${ }^{18}$ These reference standards have been calibrated to the World Health Organization (WHO) primary reference standards for $B C R-A B L 1$ RNA, four reference samples that correspond to the $B C R$ $A B L 1$ IS values of $10 \%, 1 \%, 0.1 \%$, and $0.01 \%$. Primary standards were obtained in limited quantities by diluting the K562 cell line (BCR-ABL1-positive) in the HL60 cell line $\left(B C R-A B L 1\right.$-negative). ${ }^{18}$ Another reference standard is ERM-AD623, a certified plasmid developed for the standardization of $B C R-A B L 1$ RQ-PCR ${ }^{19}$ which contains fragments of e14-a2 $B C R-A B L 1$ fusion transcripts, $B C R$ and $G U S B$. Six different concentrations of linearized plasmid were quantified by digital PCR and tested in several laboratories. The use of ERM-AD623 allows the calibration of internal reference materials to improve the accuracy of the results. According to the European Leukemia Net (ELN) recommendations, RQ-PCR analysis should be performed every 3 months until the achievement of MMR and even after the MMR is confirmed, as a close monitoring is required in view of a possible treatment discontinuation. ${ }^{20}$ If MMR is lost during follow-up, the occurrence of $A B L 1$ mutations should be investigated and molecular monitoring should be carried out more frequently. ${ }^{10,21,22}$ Follow up evaluation can be performed using PB or BM samples, and typically, both $B C R-A B L 1$ and the reference gene are tested in duplicate. ${ }^{13}$ The $B C R$ $A B L 1$ quantification is considered positive when any of the three replicates are positive, and the final number of $B C R$ $A B L 1$ and reference gene copies is the total across 
A

RNA

Standardized RQ-PCR

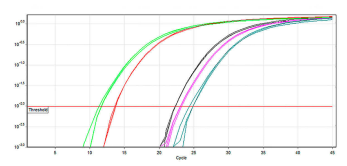

Multiplex RQ-PCR

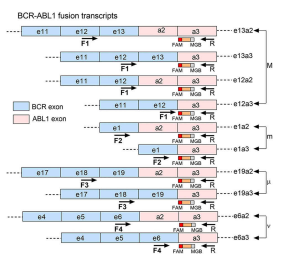

GeneXpert Dried blood spot
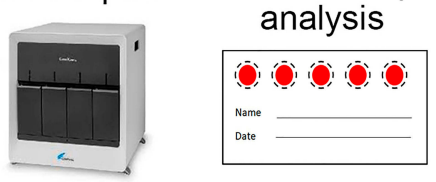

\section{Digital PCR}

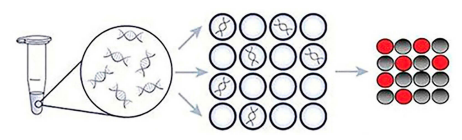

Attomolar electrochemical detection

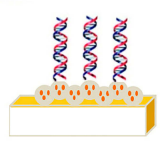

$$
\begin{aligned}
& \text { Exosome } \\
& \text { analysis }
\end{aligned}
$$

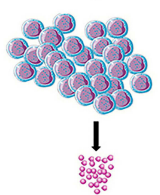

\section{BCR-ABL 1 DEPENDENT}<smiles>c1ccccc1</smiles>

DNA

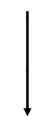

bkp identification

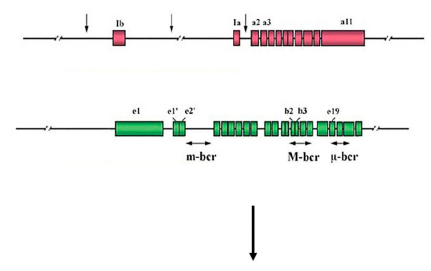

personalized monitoring

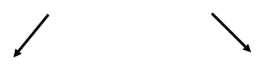

q-PCR
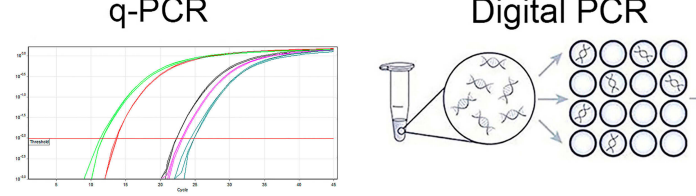

\section{PROTEIN}

Flow cytometric immunobead assay

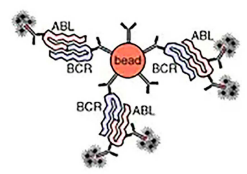

PLA-flow detection

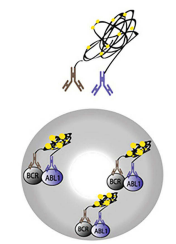

B

Single cell analysis

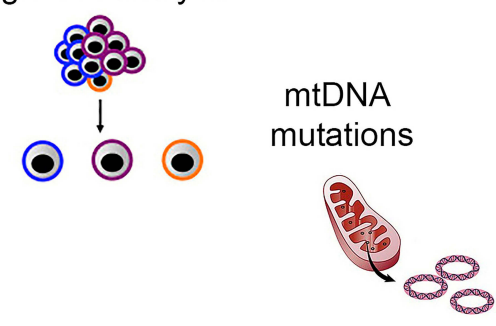

BCR-ABL 1 INDEPENDENT

CD26+ LSC identification

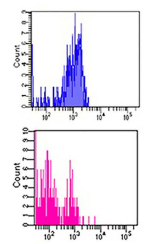

BMI protein identification

miRNA

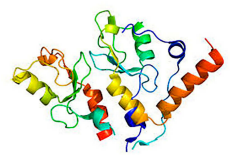

Figure I Methods for CML MRD monitoring. The strategies are based on the identification of $B C R-A B L I$ fusion $(\mathbf{A})$ or on the detection of molecular markers independent from $B C R-A B L I$ (B).

Abbreviations: bkp, breakpoint; PLA, proximity ligation assay; LSC, leukemic stem cells. 
replicates sum. When different housekeeping genes are used by different laboratories, the results can be compared using the ERM-AD623 plasmid as a RQ-PCR calibrator. ${ }^{19}$

\section{Molecular Response (MR) Milestones}

A recent version of ELN recommendations reformulated crucial aspects of CML patients molecular monitoring. ${ }^{20}$ In the past years, RQ-PCR monitoring and therapeutic improvements have led to the definition of given MR milestones at specific time-points during patient treatment. Based on the achievement of the cytogenetic and/or molecular milestones, the ELN guidelines divide CML patients into three groups: optimal response, warning and failure. ${ }^{10,20}$ The first crucial time-point is the achievement of a $B C R-A B L 1$ IS transcript level $<10 \%$ (a reduction by at least $1 \log$ of $B C R-A B L 1$ transcript levels from the standardized IS baseline) after 3 months of therapy, ${ }^{14}$ defining Early Molecular Response (EMR). EMR is considered to be a crucial treatment response, predicting the outcome of CML patients receiving either imatinib or second generation TKI, influencing event-free survival (EFS), progression-free survival (PFS), and overall survival (OS). ${ }^{23,24}$ However, not achieving EMR is considered a "warning" rather than therapy "failure" by recent ELN and European Society of Medical Oncology (ESMO) recommendations. ${ }^{10,25}$ Recent evidence showed that the kinetics of $B C R-A B L 1$ transcripts during the first 3 months is much more informative than the achievement of EMR at 3 months. The definition of "BCR-ABL1 halving time" was introduced by Branford et al in 2014, showing that patients with a halving time of less than 76 days had a better outcome, even if they did not achieve EMR at 3 months. ${ }^{26}$ These data were subsequently confirmed by other studies of CML patients receiving second generation TKI. ${ }^{27,28}$ However, the study of $B C R-A B L 1$ transcript kinetics has not yet been incorporated in follow-up recommendations, as the experimental procedure needs to be developed, such as the need for two or more consecutive quantitative analyses within the first three months and the switch to a control gene other than $A B L 1 .{ }^{14}$ The second crucial molecular milestone is achieved when the $B C R$ $A B L 1$ IS transcript level is $<1 \%$ ( $2 \log$ reduction) after 6 months of therapy. The third molecular milestone is the achievement of MMR, consisting in the reduction of the $B C R-A B L 1$ transcript level by at least $3 \operatorname{logs}\left(\mathrm{MR}^{3}\right)$ after 12 months. The definition of MMR was introduced during the IRIS (International Randomized Study of Interferon and STI-571) study, that led to imatinib registration as first line treatment. ${ }^{29}$ The availability of more potent second generation TKI allowed the identification of Deep Molecular Response (DMR), defined as a $B C R$ $A B L 1$ IS transcript level of $\leq 0.01 \%$. DMR can be further subdivided into $\mathrm{MR}^{4}, \mathrm{MR}^{4.5}$, or $\mathrm{MR}^{5}$ when the logarithmic reduction is $4,4.5$, or $5 \operatorname{logs}$, yielding $B C R-A B L 1 \leq 0.01 \%$, $\leq 0.0032 \%$, and $\leq 0.001 \%$, respectively. ${ }^{13}$ The sample is considered good quality when $A B L 1$ transcript copies are more than 10.000 (corresponding to 24.000 GUSB copies) at molecular response $\mathrm{MR}^{4}$, but the minimum $A B L 1$ copies have increased to 32.000 and 100.000 at $\mathrm{MR}^{4.5}$, and $\mathrm{MR}^{5}$, respectively. ${ }^{13}$ RQ-PCR monitoring allowed the stratification of CML patients into "optimal responders" that can continue the same TKI, "warning cases" to be considered for a possible TKI switch, and "failed patients" who do not reach molecular milestones at 3, 6, or 12 months and need an immediate change of therapy. ${ }^{10,30,31}$ The introduction of more potent and efficient second generation TKI in frontline therapy is allowing a more rapid achievement of each milestone, with a sustained deep MR. ${ }^{32,33}$

\section{Molecular Monitoring During TKI Discontinuation}

Therapeutic success of the last years allowed the achievement for most newly diagnosed CML patients of a normal life expectancy, comparable to that of age matched individuals in the general population. ${ }^{10,20}$ After survival, another crucial objective in CML clinical management is represented by the achievement of a stable DMR after long term TKI therapy, that is the prerequisite for Treatment Free Remission (TFR). The achievement of a stable DMR after long term TKI therapy is the prerequisite for Treatment Free Remission (TFR) that is the most important objective in CML clinical management. Stop Imatinib (STIM1) and TWISTER were the first two TFR pivotal studies, which enrolled patients with at least 3 years of imatinib therapy and more than 2 years of confirmed undetectable $B C R$ $A B L 1$, with a $\mathrm{MR}^{4.5}$ or $\mathrm{MR}^{5}$ sensitivity test. ${ }^{34,35}$ About $50-60 \%$ of cases in both studies showed molecular relapse (re-emergence of BCR-ABL1 transcripts or MMR loss), mostly during the first 6 months after imatinib suspension and nearly all cases regained MR after restarting treatment. Several subsequent TKI suspension studies were performed in CML patients treated with dasatinib or nilotinib for at least 2 years and maintaining durable deep MR. These studies showed TFR without molecular relapse in about 50 to $69 \%$ of cases. ${ }^{34,36-38}$ As regards recommendations on discontinuation criteria, the National Comprehensive Cancer Network (NCCN) guidelines and 
other expert reviews suggested the selection of patients with a non-high Sokal score, showing a typical $B C R-A B L 1$ transcript (b2a2 or b3a2) and a $\mathrm{MR}^{4}$ or $\mathrm{MR}^{4.5}$ level of molecular response for a minimum of 1-2 years under TKI therapy. ${ }^{11,39,40}$ More stringent TFR criteria were defined by recent ELN recommendations, requiring typical $B C R$ $A B L 1$ transcripts, a minimal TKI therapy duration of 4-5 years, and a DMR (MR ${ }^{4}$ or better) duration of more than 2 years. ${ }^{20} \mathrm{~A}$ durable DMR is considered a more important selection criterion than the duration of TKI treatment, ensuring a greater TKI discontinuation success. ${ }^{39}$ Because of the high frequency of molecular relapse, TFR trials require monthly RQ-PCR monitoring for the first 6 to 12 months, with a possible gradual reduction thereafter. ${ }^{20,34,41,42}$ However, RQ-PCR might not be the best approach for selecting CML cases to include in TKI discontinuation trials and also for molecular monitoring during TFR, as $50-60 \%$ of patients with undetectable DMR are expected to lose MMR. ${ }^{43-45}$ Several studies have demonstrated the persistence of leukemic cells in the BM niche of CML patients treated with TKI and with undetectable $B C R-A B L 1$ transcript levels by RQPCR. A recent flow cytometry study showed the presence of circulating CD26+ leukemic stem cells (LSC) in about $30 \%$ of CML patients with undetectable $B C R-A B L 1$ by RQ-PCR. ${ }^{46}$ Failure to detect the $B C R-A B L 1$ transcript could be attributed to low RQ-PCR sensitivity or to absent gene transcription in quiescent LSC that reside in a hypoxic niche. ${ }^{47}$ To address this issue, new more sensitive methodologies have been investigated to identify possible residual LSC and to allow a more accurate selection of CML patients likely to benefit from TFR.

\section{$B C R-A B L I$ Transcript Monitoring by Digital PCR (dPCR)}

In the last years, $\mathrm{dPCR}$ has revolutionized the molecular monitoring of MRD in hematological diseases. ${ }^{48-52} \mathrm{dPCR}$ is the most accurate and sensitive method for measuring the abundance of specific nucleic acids, providing their absolute quantification and offering a greater precision and reproducibility compared to RQ-PCR ${ }^{53,54}$ Recent studies showed that dPCR is more efficient than RQ-PCR for CML MRD monitoring and for a more accurate selection of patients eligible for TFR. ${ }^{55-59}$ In dPCR the biological sample analyzed is divided into thousands or millions of separate reactions and amplification is performed with a higher efficiency in many separate microscopic partitions, in wells or droplets (ddPCR) ${ }^{60}$ Each partition is evaluated as positive or negative, according to the presence or absence of template molecules and the nucleic acids copy number in the starting sample is identified by Poisson statistics. ${ }^{61}$ In this way, an absolute quantification can be performed with a greater sensitivity and without the need for a standard curve. ${ }^{62}$ dPCR is considered able to detect a single $B C R-A B L 1$ positive cell out of $10^{7}$ and is less subject to inhibitory agents and nonspecific amplification. ${ }^{55,56}$ Several independent studies demonstrated a greater sensitivity of dPCR as compared to RQPCR, demonstrating a significant percentage of CML cases that lost TFR and were found to be $B C R-A B L 1$ positive by dPCR. Moreover, cases in follow-up showing the loss of DMR by RQ-PCR were identifiable by dPCR within 3 months before. ${ }^{57,59,63,64}$ Recent studies, such as Life After Stopping Tyrosine Kinase Inhibitors (LAST) and the Imatinib Suspension and Validation (ISAV) are investigating the efficacy of $\mathrm{dPCR}$ for the molecular monitoring of patients with undetectable $B C R-A B L 1$ who have suspended TKI therapy. ${ }^{65,66}$ Because of several advantages and high sensitivity, dPCR has been used to evaluate the circulating tumor burden in cancer research and for the quantification of circulating tumor DNA in plasma from solid neoplasms. ${ }^{67}$ Recently, dPCR has been employed for the quantification of the $B C R-A B L 1$ transcript in exosomes from PB of CML patients under TKI treatment, ${ }^{68}$ demonstrating its success as a possible innovative monitoring system based on exosomes analysis. Exosomes are extracellular vesicles (EVs) secreted by living cells exocytosis mediating intracellular and microenvironment communication. They are lipid nanoparticles $(50-100 \mathrm{~nm})$ produced either constitutively or upon induction, and their molecular composition depends on the parent cell origin. ${ }^{69,70}$ To date, exosomes have been especially employed for the diagnosis of solid tumors on the basis of their internal proteins and nucleic acids, or on the membrane surface expression of cancer-specific antigens. Moreover, exosomes have also been isolated from leukemic cells and can be utilized as prognostic, diagnostic and therapeutic biomarkers in different hematologic neoplasms, such as acute myeloid leukemia, multiple myeloma and chronic lymphocytic leukemia. ${ }^{71-74}$ Microvesicles released by the K562 cell line have been reported to contain both $B C R-A B L 1$ DNA and transcript and are able to induce the CML phenotype in transplanted rats, or can activate BM mesenchymal stem cells promoting leukemic cells proliferation. ${ }^{75,76} \mathrm{Few}$ data are available on the identification and quantification of $B C R-A B L 1$ in exosomes from CML patients, generally isolated from $\mathrm{PB}$. In the explorative study by Bernardi 
et al, ten CP-CML patients were analyzed by RQ-PCR and dPCR on both PB cells and on tumor-enriched exosomes, demonstrating the presence of the $B C R / A B L 1$ transcript in exosomes derived from CML patients. However these are very preliminary data, therefore the clinical and prognostic significance of $B C R-A B L 1$ positive exosomes and their use in CML molecular monitoring remains to be investigated. ${ }^{68}$ However, despite several advantages and applications, dPCR shows some limits as it generally requires a longer experimental time and can be conditioned by errors in pre-analytical phases such as sampling, RNA extraction and cDNA synthesis. Moreover, positive and negative control samples are needed, the quantification of a reference gene is still useful to evaluate the sample quality, and the use of a $\mathrm{CF}$ is required for the expression of results according to the IS. ${ }^{77}$ Therefore, international standardization is needed before $\mathrm{dPCR}$ can be adopted as a routine molecular method for CML monitoring.

\section{The GeneXpert System}

The GeneXpert system is a cartridge-based RQ-PCR automated method developed by Cepheid (California, USA), that is able to detect $B C R-A B L 1$ p210 transcripts when directly processing PB samples. The GeneXpert instrument utilizes microfluidics in a cartridge and performs RNA extraction, RT-PCR and $B C R-A B L 1$ fluorescence detection in one reaction. ${ }^{78}$ This is a very simple, fast system, requiring a reduced technical expertise. The RQ-PCR is performed within a cartridge not reporting $B C R-A B L 1$ transcript levels on the IS; therefore a specific CF needs to be developed and used in addition to a cartridge lotspecific calibration, in order to obtain the $B C R-A B L 1$ estimation on IS. ${ }^{79,80}$ Recent studies demonstrated a good correlation between the standardized RQ-PCR and the GeneXpert systems for $B C R-A B L 1$ monitoring, ${ }^{79,81}$ and a new cutoff of $1.5 \%$ at 3 months has been proposed as predictive of both cytogenetic and molecular response at 12 months. ${ }^{82}$ Secondly, the initial accuracy of the $B C R-A B L 1$ test on the GeneXpert, fails at very low transcript levels, below $0.01 \%$ BCR-ABL1 $\left(\mathrm{MR}^{4}\right) ;{ }^{79,83}$ however, soon after Cepheid introduced a GeneXpert assay with an enhanced sensitivity at a level of $\mathrm{MR}^{4.5}$ on the IS. ${ }^{84}$ Moreover, atypical rare $B C R-A B L 1$ transcripts cannot be identified by the current GeneXpert $B C R-A B L 1$ assay; therefore, all negative suspected CML cases have to be screened by other molecular methods. ${ }^{85}$ Another development of the GeneXpert system is the $B C R-A B L 1$ transcript quantification on a paper template consisting of dried blood spots
(DBSs). ${ }^{86}$ About $200 \mu \mathrm{L}$ of PB were spotted on filter paper and analyzed after about 40 days; this study showed a high concordance between DBSs and fresh blood samples, with a high correlation $\left(R^{2}=0.94\right)$, revealing that this assay can work on RNA, despite it being less stable than DNA. An accurate $B C R-A B L 1$ transcript quantification can be obtained on DBSs, in addition to a possible $A B L$ mutation detection on DNA. This system is especially useful for lowresource regions in the world, that could send samples to specialized centers at very low cost. ${ }^{86}$

\section{The Attomolar Electrochemical Detection}

A new system for the detection of $B C R-A B L 1$ chimeric transcript has recently been developed using an electrochemical DNA biosensor based on polyaniline-gold nanoparticles. ${ }^{87}$ cDNA samples from CML cases exposed to the biosensor surface, hybridize with fusion genespecific DNA probes and induce changes in the amperometric current. The hybridization between the biosensor and the target cDNA can be evidenced by Atomic force microscopy (AFM) images, that show dramatic changes in the surface of the nanostructured platform after exposure to CML samples. This electrochemical biosensor is a fast, simple, and innovative tool for the molecular detection of the $B C R-A B L 1$ transcript, displaying high specificity and sensitivity. It can detect concentrations as low as 0.0694 $\mathrm{fM}$ of recombinant plasmid containing the $B C R-A B L 1$ fusion gene. Even if it is difficult to compare this detection limit with the $B C R-A B L 1$ levels on IS, this is the lowest concentration at which the $B C R-A B L 1$ transcript was detected; the biosensor can therefore be considered a useful method for MRD monitoring in CML. Other $B C R-A B L 1$ biosensors had previously been developed, but featured a longer platform construction time and higher limit of fusion gene detection. ${ }^{88,89}$

\section{Atypical BCR-ABLI Transcripts}

About $2 \%$ of CML patients show atypical $B C R-A B L 1$ transcripts, different from the most common e13a2 (b2a2) and e14a2 (b3a2) isoforms, that can be identified by the concomitant contribution of conventional cytogenetics, FISH, and RT-PCR. Variant $B C R-A B L 1$ transcripts are often e1a2 or e18/e19a2. Some studies suggested that CML patients with variant isoforms had a worse outcome than cases with the typical $B C R-A B L 1$ fusion, but few data are available on their long-term outcomes because of the rarity of these cases. $^{90}$ A study was recently performed on $4750 \mathrm{CML}$ patients and a total of 19 uncommon transcripts were 
detected in $83(1.7 \%)$ patients. $^{91}$ The three most frequent types were e19a2, e13a3/e14a3 and e1a2. Patients carrying e19a2 $(n=16)$ and e1a2 $(n=11)$ transcripts, had significantly reduced probabilities of 1-year complete cytogenetic response and MMR compared with patients with common e13a2 and e14a 2 transcripts, receiving frontline imatinib therapy. Moreover, cases with the e19a2 transcript had low probabilities of 2-year EFS and PFS and patients with the ela2 transcript had low probability of 2-year EFS. ${ }^{91}$ In other words, the rare uncommon $B C R-A B L 1$ fusion transcripts may be relevant for TKI therapy outcomes. In view of these data, the MRD monitoring of these patients gains relevance. Most laboratories do not carry out RQ-PCR for atypical $B C R-A B L 1$ transcripts, as standardization to the IS has not yet been performed for variant isoforms, so the MMR evaluation cannot be accurately performed in these CML patients. In these cases, follow-up monitoring is usually performed by FISH or by conventional nested RTPCR; otherwise, patient-specific primers and probe may be employed in RQ-PCR or dPCR. ${ }^{90,92}$ A new multiplex RQPCR method that is able to detect at least 14 different possible isoforms of the $B C R-A B L 1$ fusion gene in one reaction with high sensitivity and specificity, has recently been developed to allow both precise CML diagnosis and MRD monitoring. ${ }^{93}$ This method is fast, simple and cheap, shows sensitivity up to $10^{-6}$ copies and is able to detect several possible major (M-bcr), minor (m-bcr), micro ( $\mu$ bcr), and nano (n-bcr) bcr BCR-ABL1 isoforms. ${ }^{93}$ On the other hand, most of the RQ-PCR methods currently used are able to detect only a few $B C R-A B L 1$ isoforms at a time, such as e13a2, e14a2 and e1a2. Other multiplex RT-PCR methods have previously been developed, but show low sensitivity or are laborious to carry out. ${ }^{94,95}$

\section{Alternatively Spliced $B C R-A B L I$ Variants}

Conventional and standardized $B C R-A B L 1$ monitoring by RQ-PCR cannot distinguish between the classic $B C R$ $A B L 1$ transcript and different isoforms or abnormal splicing variants. It is therefore crucial to identify conventional $B C R-A B L 1$ transcripts in order to obtain an accurate MRD evaluation and to distinguish variant isoforms possibly responsible for therapy resistance. Recently, a new sensitive system has been developed, based on long-range PCR amplification and ultra-deep sequencing (UDS), that is able to identify and quantify both conventional and variant or mutated $B C R-A B L 1$ transcripts. ${ }^{96}$ An outer and an inner set of $B C R$ and $A B L 1$ primers were designed to amplify several possible mutant or variant fusion isoforms; these large amplicons of $B C R-A B L 1$ transcripts were used for library preparation and subjected to UDS. This analysis allowed the identification of the mutated $B C R-A B L 1^{\text {Ins } 35 \mathrm{pb}}$ isoform causing a conformational change in the chimeric protein, in all CML cases showing a suboptimal response to TKI therapy. This isoform cannot be distinguished from the conventional $B C R-A B L 1$ transcript by standardized RQ-PCR, thus causing an improper categorization of the molecular response. Moreover, it has been hypothesized that the $B C R-A B L 1^{I n s 35 p b}$ isoform is expressed in quiescent LSC, that continue to proliferate slowly.

\section{DNA-Based Approaches}

In the last decade, the use of RNA as input material for MRD molecular monitoring has many times been reconsidered in favor of genomic DNA. In fact, CML patients shown by RQ-PCR to maintain a complete molecular response after stopping imatinib treatment were demonstrated to have evidence of persistent leukemic cells by DNA PCR. ${ }^{97}$ The DNA-based assay was found to have a greater sensitivity than the standardized RNA quantification, yielding a lower detection limit of $10^{-6}$ and this is the major advantage of the use of DNA-based MRD monitoring in CML. In fact, the quantification of MRD by genomic DNA enables an estimation of cells number, unaffected by mRNA expression levels and mRNA stability. ${ }^{97}$ However, even if more sensitive, the choice of DNA as input material requires a two-steps approach for the molecular MRD monitoring of CML patients. The first laborious step is the patient-specific $B C R-A B L 1$ breakpoint characterization (Table 1). This is the main obstacle, in fact, unlike the $B C R$ gene, the $A B L 1$ gene possible breakpoint sites span a region of about $150 \mathrm{Kbps}$. The second step consists in the molecular quantification of leukemic cells in the CML patient using different methodological strategies. In the last years, several strategies have been tested for this two-steps approach, as reported below.

\section{Patient-Specific BCR-ABLI Breakpoint Characterization} Different methodological approaches have been developed with the aim to simplify the laborious step of patient-specific $B C R-A B L 1$ breakpoint characterization. A protocol based on long-range PCR (using a constant $B C R$-primer and $10 A B L 1$ primers at a distance of approximately $15 \mathrm{~kb}$ each) and automated DNA sequencing has been proposed. ${ }^{98}$ Other authors used a PCR system originally developed for genome walking ${ }^{99,100}$ based on DNA fragmentation, adaptors ligation, nested-PCR amplification using adaptor-specific 
Table I Different Approaches for BCR-ABLI Genomic Breakpoint Characterization

\begin{tabular}{|l|l|l|l|}
\hline Sequencing Approach & Technical Strategy & Advantages & Disadvantages \\
\hline SS & $\begin{array}{l}\text { Long-range PCR and SS } \\
\text { Genome walking and SS } \\
\text { SHP-PCR and SS } \\
\text { FISH, Long-range PCR and SS }\end{array}$ & Affordable technologies & Laborious and time-consuming protocols \\
\hline \multirow{2}{*}{ NGS } & $\begin{array}{l}\text { Long-range PCR and 454 technology } \\
\text { Short-read NGS technology }\end{array}$ & Easier protocols & Expensive technologies \\
\cline { 2 - 4 } & Long-range PCR and MinION technology & $\begin{array}{l}\text { Affordable technologies } \\
\text { Easy and rapid protocols }\end{array}$ & Higher error-rate \\
\hline
\end{tabular}

Abbreviations: SS, sanger sequencing; NGS, next generation sequencing; SHP-PCR, sequential hybrid primer PCR; FISH, fluorescent in situ hybridization.

primers and Sanger sequencing (SS). ${ }^{101,102}$ Subsequently, the Sequential Hybrid Primer PCR (SHP-PCR) was developed. The strategy combines a primary highly multiplexed PCR (six forward primers mapping on $B C R$ and 302 reverse primers mapping on $A B L 1$ ) followed by two rounds of nested-PCR (to removing nonspecific amplification) and SS. ${ }^{103-105}$ Breakpoint characterization was also performed by long-range PCR (using a single forward primer in $B C R$ and a panel of 20 reverse primers spanning both alternative first exons of $A B L 1$ ) and SS. ${ }^{97,106}$ To simplify this method, narrowing the genomic area of analysis by FISH assays (preliminarily performed using seven overlapping fosmid clones) was proposed, reducing from 20 to three the number of $A B L 1$ reverse primers to be used in three subsequent longrange PCRs. ${ }^{107}$ An analogous approach was used to characterize and compare breakpoint sequences in p210 CML, p210 ALL and p190 ALL. ${ }^{108}$ In the pediatric CML context, a tworound multiplex long-range PCR was developed, designing five nested primer pairs covering the major breakpoint cluster region (M-BCR) of the $B C R$ gene, and 20 nested primer pairs covering the $A B L 1$ breakpoint cluster region. ${ }^{109,110}$ The advent of next generation sequencing (NGS) has greatly facilitated the breakpoint characterization step, even if it offers this opportunity only to laboratories that can afford a major investment in this type of technology. Some authors set up a strategy based on the generation of large amplicons by a two-round multiplex long-range $\mathrm{PCR}^{97,98}$ and subsequent ultra-wide sequencing using 454 NGS technology. ${ }^{111}$ Two other groups performed an approach based on short-read sequencing (Illumina technology). ${ }^{112,113}$ The study of structural variants by conventional NGS approaches, remains affected by the limit of the reads length. For this reason, for the $B C R-A B L 1$ breakpoint characterization, the MinION, a third generation long-read nanopore-based sequencer, already tested in the hematological field, ${ }^{114-118}$ has been proposed. The length of the reads produced and the platform accessibility in term of costs and ease of use, make the technology ideal for this intent. ${ }^{107}$

\section{Leukemic Cells Molecular Quantification}

Sequencing of the region spanning the $B C R-A B L 1$ genomic breakpoint is aimed at designing a patient-specific pair of primers for the molecular quantification of leukemic cells in the CML patient PB. The first attempts were based on real time quantitative PCR (qPCR) ${ }^{101,102,105,109}$ that some authors performed as nested qPCR. ${ }^{97,104}$ The comparison of qPCR on genomic DNA with the standardized RQ-PCR on RNA, shows an excellent correlation $(\mathrm{r}=0.884 ; p<0.0001)^{105}$ but had better precision at low minimal residual disease levels, ${ }^{97,102,104,105}$ where genomic DNA could be more informative than mRNA for the detection of residual disease or for very immature selected progenitors. ${ }^{98}$ Furthermore, the use of DNA presents two other technical advantages: the handling of a stable molecule instead of RNase sensitive RNA and the use of patient-specific primers thus minimizing the PCR contamination risk. ${ }^{98}$ In the last years, different approaches have been made to test the dPCR performances on genomic $B C R-A B L 1$ quantification. ${ }^{106,107,110,112}$ Recently, a comparison between RQ-PCR, qPCR, RT-dPCR and dPCR in the detection of low levels of $B C R-A B L 1$ positive disease was made. ${ }^{112}$ The authors demonstrated that $\mathrm{DPCR}$ for $B C R-A B L 1$ DNA is the most sensitive method available for residual-disease detection in CML and may prove useful in the management of TKI withdrawal. Furthermore, dPCR on DNA and RQ-PCR on RNA were performed in parallel to determine the relative contribution of the leukemic cell number to molecular response in 516 paired samples from 59 newly-diagnosed patients treated with first-line imatinib in the TIDEL-II study. ${ }^{106}$ The study 
clarified the kinetics of molecular response in CML, showing that in the first three months of treatment, the rapid decline in $B C R-A B L 1 \mathrm{mRNA}$ is due to a reduction in both cells number and transcripts level per cell. On the contrary, beyond three months, the $B C R-A B L 1$ mRNA decrease is proportional to the leukemic cells depletion. Moreover, the results confirmed the greater sensitivity of $\mathrm{dPCR}$, in fact $B C R-A B L 1$ DNA was quantifiable in $48 \%$ of undetectable $B C R-A B L 1$ mRNA samples, making MRD quantifiable for an additional 5-18 months (median 12 months). ${ }^{106}$ The greater sensitivity of the DNA-based assay, that has been widely demonstrated in the last years, could be especially interesting in the case of the TKI-discontinuation in CML. In this crucial step of MRD monitoring, this approach may help to distinguish those patients who can from those who should not undergo discontinuation. ${ }^{119}$ In fact one of the primary aims of the MRD monitoring is to avoid relapse, that occurs in about $50 \%$ of patients achieving and maintaining deep molecular response who stop TKI therapy. ${ }^{120}$

\section{Protein-Based Approaches}

The chimeric BCR-ABL1 protein was considered as a possible detection target to detect for CML MRD monitoring. For this purpose, a flow cytometric immunobead assay for the detection of BCR-ABL1 fusion proteins (p190, p210 and p230) in cell lysates was developed. ${ }^{121}$ The approach, using a bead-bound anti-BCR catching antibody and a fluorochrome-conjugated anti-ABL1 detection antibody, was tested on 145 samples (BM or PB) and showed full concordance with RT-PCR of fusion gene transcripts. The limit of detection calculated analyzing serial dilutions of three BCR-ABL1 positive cell lines (TOM-1, K562 and AR230) showed a sensitivity of at least $1 \%$, higher than karyotyping (around 5\%) and FISH (2-4\%), but lower than the PCR technique. ${ }^{121}$ The assay, commonly named the CBA (cytometric bead array) system, was subsequently adopted by other authors and tested in different BCR-ABL1 positive hematological diseases. ${ }^{122,123}$ It was demonstrated to be a rapid, easy technique for specific detection of BCR-ABL1 proteins in leukemic cells. The technique is independent of the $B C R$ gene breakpoint, does not need special laboratory facilities other than a routine flow cytometer, and yields results in around four hours. This could be useful in countries where molecular diagnostics is not readily available to support clinical practice. ${ }^{121}$ Furthermore, a novel approach to detecting and enumerating cells positive for the BCR-ABL1 fusion protein was recently proposed. ${ }^{124}$ The technique combines the in situ proximity ligation assay with flow cytometry as readout (PLA-flow). The BCR and ABL1 parts of the chimeric protein are targeted with an antibody each, the fluorescent signals are amplified by rolling circle amplification and the BCR-ABL1 positive cells are detected at frequencies as low as one in 10.000. The PLA-flow test is strongly correlated to the RQ-PCR technique, both at disease diagnosis and for MRD monitoring during follow-up. Since it allows simultaneous immunostaining of additional cell markers, it makes it possible to identify specific cell populations involved in CML disease progression. $^{124}$

\section{$B C R-A B L I$ Independent MRD Monitoring Residual LSC Identification}

Single cell sequencing (SCS) technologies, based on single cells isolation and amplification of genetic material, have recently been developed. ${ }^{125}$ It is now possible to analyse genomic, transcriptomic, and epigenomic information in single cancer cells, better defining the basis of clonal heterogeneity. SCS may also allow MRD monitoring in hematological malignancies by sequencing circulating tumor cells (CTCs) from PB. In a recent study a whole transcriptome approach, Smart-seq2, was employed to detect the $B C R-A B L 1$ gene in single cells isolated from the $\mathrm{K} 562$ cell line. ${ }^{126}$ This study showed that CML LSC resistant to TKI had a different transcriptome from that of normal hematopoietic stem cells (HSCs) and drug resistance specific mutations were also revealed. ${ }^{126}$ Moreover, further singlecell studies showed that TKI therapy induced genetic changes in CML LSC, as different subclones were observed in CML patients at diagnosis and after TKI treatment. ${ }^{127}$ Single cell methods allowed a better identification and characterization of CML LSC distinguishing them from healthy stem cells, by combining gene expression analysis and the screening of cell surface markers. These systems allowed a $\mathrm{Lin}^{-} \mathrm{CD} 34^{+} \mathrm{CD} 38^{-} \mathrm{CD} 4 \mathrm{RA}^{-} \mathrm{CKIT}^{-} \mathrm{CD} 26^{+}$population to be identified as a potential therapeutic target in cases of CML relapse. ${ }^{127}$ These kinds of approach may be useful to identify and study the rare CML cases characterized by the presence of concomitant driver genes mutations. ${ }^{128,129}$

\section{CD26+ LSC Detection}

The CD26 antigen (dipeptidyl-peptidase IV, DPPIV) has been identified as a potential biomarker for the isolation of LSC in BM samples of CML cases, as it is specifically expressed on all leukemic cells from CML patients but not present on normal BM cells or on leukemic cells from other 
neoplasms. ${ }^{130} \mathrm{CD} 26$ has been proposed to have a crucial role in the interaction between LSC and the BM niche and the resistance to TKI therapy. ${ }^{131}$ Moreover, it has been demonstrated that CD26+ LSC from BM of CML patients are characterized by the expression of $B C R-A B L 1$ transcripts and their number decreases during TKI treatment, ${ }^{130}$ suggesting that they can be used as a useful marker for MRD monitoring. ${ }^{132}$ However, the CD26+ LSC number was independent of the $B C R-A B L 1$ expression, as an increase from diagnosis to the third month of follow-up was revealed, and then a reduction during imatinib therapy. ${ }^{133}$ A recent study demonstrated that a more practical monitoring can be performed by CD26+ LSC flow cytometry on CML patients PB samples. CD26 expression was detected on CD45+/CD34 +/CD38- blood samples within $24 \mathrm{~h}$, at diagnosis, during follow-up, and during TFR, ${ }^{46}$ showing the persistence of residual circulating CD26+ LSC even in most of the CML patients with undetectable $B C R-A B L 1$. No correlation was revealed between LSC persistence and the use of specific TKI or between the absolute number of PB CD26+ LSC and the $B C R-A B L 1$ transcript level according to the IS. These data showed that quiescent residual CML LSC may be transcriptionally silent and so not detectable by RQ-PCR or by other molecular systems investigating the $B C R-A B L 1$ transcript. However, the opportunity of monitoring residual PB CD26+ LSC, in addition to standard $B C R-A B L 1$ molecular detection, is being investigated in other currently ongoing studies.

\section{Polycomb BMII Protein Identification}

The Polycomb gene BMII is expressed in $\mathrm{Ph}$ negative chronic myeloid neoplasms, in follicular lymphoma, in acute myeloid leukemia, and in advanced CML phases and is associated with a poor prognosis. BMI1 supports the self-renewal of both HSC and LSC, cooperating with $B C R-A B L 1$ in stimulating cell proliferation. ${ }^{134} B M I 1$ is overexpressed in CML compared to healthy individuals and shows an increased expression during disease progression. ${ }^{135}$ A recent study showed that BMI1 could be a new, valid marker of response to TKI therapy in CML, independently of the $B C R-A B L 1$ transcript level. ${ }^{133}$ It has been observed that the BMII expression increases after diagnosis, whereas a good correlation with standard molecular response is revealed after the third month of therapy. BMI1 protein expression was detected by immunofluorescence assays and confocal microscopy in CD26+ LCS from CML cases expressing the BCR-ABL1 protein, therefore not allowing a quantitative determination.

\section{MicroRNAs (miRNAs) Quantification}

To determine alternative biomarkers to discriminate which patients can safely and successfully discontinue imatinib use, miRNAs expression quantification has also been considered. Using a TaqMan miRNA array on PB mononuclear cells (PBMCs), the miRNAs expression profile was studied in five patients who had discontinued imatinib (STOP-IM group), seven CML patients receiving imatinib (IM group), and five healthy volunteers (HV). ${ }^{136}$ Among 22 differently expressed miRNAs, three of them (let-7b, miR-148b, and miR-326) were selected for a further validation by RQ-PCR in 16 patients of the STOP-IM group, 33 of the IM group, and 15 HV. Downregulation of miR$148 \mathrm{~b}$ was observed in the STOP-IM group patients and in a subset of the IM group with a higher sustained undetectable minimal residual disease (UMRD) and a higher percentage of natural killer cells. These preliminary results support the idea that circulating PBMCs miR-148b may contribute to immune surveillance in STOP-IM patients and may therefore have a potential role as a biomarker for the safe discontinuation of IM. ${ }^{136}$ Later, the exosome and plasma miRNAs contribution was also considered. A preliminary screening of candidate miRNAs in seven STOP-IM group patients compared with seven HV, identified a downregulation of exosome and plasma miR-215 in the STOP-IM group compared to the controls. ${ }^{137}$ Furthermore, the plasma miRNA-215 level was significantly downregulated in 20 STOP-IM cases $(p<0.0001)$ compared to 32 patients with UMRD in the IM group and $28 \mathrm{HV}$. The low plasma miR-215 level was also significantly correlated $(p=0.0229)$ to a higher total IM intake. These observations suggest a possible role of plasma miR215 (mirror of exosome miR-215) in successful IM discontinuation. ${ }^{137}$ Further studies will be required to reveal the biological and clinical significance of miRNAs in CML pathogenesis and the potential role of these molecules as alternative biomarkers for the molecular monitoring of patients in treatment discontinuation.

\section{Mitochondrial DNA (mtDNA) Mutations Detection}

Recent evidences showed that somatic mtDNA mutations frequently occur in many human solid and hematologic neoplasms. ${ }^{138}$ A study by Pagani et al, developed a new approach based on long-range PCR and NGS for the identification of mtDNA mutations in CML cases under TKI therapy. ${ }^{138}$ Because of the low frequency and extreme 
heterogeneity of these mutations, specific software for variant identification must be used to reduce error rate and false-positive results. Several somatic mutations were found in CML diagnosis samples at a higher average rate than that reported in other cancers; about $48 \%$ of mutations were detected in noncoding DNA or were synonymous mutations. Many of the identified variants showed a frequency too low to be validated by SS. Some somatic mutations were detected in both diagnosis and remission samples, probably because of the persistence of residual leukemic cells. These preliminary data showed that the identification of somatic mtDNA mutations in CML patients could be useful for monitoring the response to TKI therapy and for a better selection of patients eligible for TFR.

\section{Closing Remarks}

The introduction of TKI in CML treatment has totally revolutionized patient management but demands ever more efficient MRD monitoring strategies. Although $B C R-A B L 1$ transcript quantification by RQ-PCR remains the gold standard method, several approaches have been developed in the last decade with the aim of improving this practice. One of the main limits of CML MRD monitoring is the poor ability to detect LSC persistent in the BM of patients with sustained undetectable molecular residual disease. ${ }^{139}$ In fact, the BM microenvironment may provide survival signals that contribute to the failure to eliminate these residual cells that could cause disease relapse. ${ }^{140}$ To overcome this drawback, different new monitoring strategies have been developed and tested. The introduction of new techniques and the possibility to detect targets other than the $B C R-A B L 1$ chimeric transcript, can improve the disease detection, in terms of accuracy, sensitivity and specificity, but require a long validation step, as well as a standardization process before their introduction into clinical practice. In the precision medicine era, the constant improvement of the CML MRD monitoring practice could allow clinicians to choose the best therapeutic algorithm, and in particular aid the selection of patients eligible for TKI discontinuation. In fact, an ever more efficient monitoring protocol could reduce the high percentage of relapses in treatment-free remission cases, thus improving the disease management and the life expectancy of CML patients.

\section{Acknowledgments}

The authors would like to thank Ms. MVC Pragnell, B.A., for language revision of the manuscript.

\section{Funding}

This work was supported by "Associazione Italiana contro le Leucemie (AIL)-BARI".

\section{Disclosure}

The authors declare no competing interests.

\section{References}

1. Nowell PC, Hungerford DA. Chromosome studies on normal and leukemic human leukocytes. $J$ Natl Cancer Inst. 1960;25:85-109.

2. Melo JV, Barnes DJ. Chronic myeloid leukaemia as a model of disease evolution in human cancer. Nat Rev Cancer. 2007;7 (6):441-453. doi:10.1038/nrc2147

3. Hehlmann R, Lauseker M, Saußele S, et al. Assessment of imatinib as first-line treatment of chronic myeloid leukemia: 10-year survival results of the randomized CML study IV and impact of non-CML determinants. Leukemia. 2017;31(11):2398-2406. doi:10.1038/leu.2017.253

4. Chereda B, Melo JV. Natural course and biology of CML. Ann Hematol. 2015;94(2):107-121. doi:10.1007/s00277-015-2325-z

5. Rossi AR, Breccia M, Abruzzese E, et al. Outcome of 82 chronic myeloid leukemia patients treated with nilotinib or dasatinib after failure of two prior tyrosine kinase inhibitors. Haematologica. 2013;98(3):399-403. doi:10.3324/haematol.2012.064337

6. Soverini S, De Benedittis C, Mancini M, Martinelli G. Best practices in chronic myeloid leukemia monitoring and management. Oncologist. 2016;21(5):626-633. doi:10.1634/theoncologist.20150337

7. Ross DM, Hughes TP. How I determine if and when to recommend stopping tyrosine kinase inhibitor treatment for chronic myeloid leukaemia. Br J Haematol. 2014;166(1):3-11. doi:10.1111/bjh.12892

8. Ben Lassoued A, Nivaggioni V, Gabert J. Minimal residual disease testing in hematologic malignancies and solid cancer. Expert Rev Mol Diagn. 2014;14(6):699-712. doi:10.1586/14737159.2014.927311

9. Gabert J, Beillard E, van der Velden VHJ, et al. Standardization and quality control studies of "real time" quantitative reverse transcriptase polymerase chain reaction of fusion gene transcripts for residual disease detection in leukemia - A Europe Against Cancer Program. Leukemia. 2003;17(12):2318-2357. doi:10.1038/ sj.leu.2403135

10. Baccarani M, Deininger MW, Rosti G, et al. European LeukemiaNet recommendations for the management of chronic myeloid leukemia: 2013. Blood. 2013;122(6):872-884. doi:10.11 82/blood-2013-05-501569

11. Radich JP, Deininger M, Abboud $\mathrm{CN}$, et al. Chronic myeloid leukemia, version 1.2019, NCCN clinical practice guidelines in oncology. J Natl Compr Cancer Netw. 2018;16(9):1108-1135. doi:10.6004/jncen.2018.0071

12. Cross NCP, White HE, Müller MC, Saglio G, Hochhaus A. Standardized definitions of molecular response in chronic myeloid leukemia. Leukemia. 2012;26(10):2172-2175. doi:10.1038/leu.20 12.104

13. Cross NCP, White HE, Colomer D, et al. Laboratory recommendations for scoring deep molecular responses following treatment for chronic myeloid leukemia. Leukemia. 2015;29(5):999-1003. doi:10.1038/leu.2015.29

14. Hughes T, Deininger M, Hochhaus A, et al. Monitoring CML patients responding to treatment with tyrosine kinase inhibitors: review and recommendations for harmonizing current methodology for detecting BCR-ABL transcripts and kinase domain mutations and for expressing results. Blood. 2006;108(1):28-37. doi:10.1182/ blood-2006-01-0092 
15. Branford S, Cross NCP, Hochhaus A, et al. Rationale for the recommendations for harmonizing current methodology for detecting BCR-ABL transcripts in patients with chronic myeloid leukaemia. Leukemia. 2006;20(11):1925-1930. doi:10.1038/sj.leu.2404388

16. Cross NCP. Standardisation of molecular monitoring for chronic myeloid leukaemia. Best Pract Res Clin Haematol. 2009;22 (3):355-365. doi:10.1016/j.beha.2009.04.001

17. Branford S, Fletcher L, Cross NCP, et al. Desirable performance characteristics for BCR-ABL measurement on an international reporting scale to allow consistent interpretation of individual patient response and comparison of response rates between clinical trials. Blood. 2008;112(8):3330-3338. doi:10.1182/blood-2008-04150680

18. White HE, Hedges J, Bendit I, et al. Establishment and validation of analytical reference panels for the standardization of quantitative BCR-ABL1 measurements on the international scale. Clin Chem. 2013;59(6):938-948. doi:10.1373/clinchem.2012.196477

19. White H, Deprez L, Corbisier P, et al. A certified plasmid reference material for the standardisation of BCR-ABL1 mRNA quantification by real-time quantitative PCR. Leukemia. 2015;29(2):369-376. doi:10.1038/leu.2014.217

20. Hochhaus A, Baccarani M, Silver RT, et al. European LeukemiaNet 2020 recommendations for treating chronic myeloid leukemia. Leukemia. 2020:966-984. doi:10.1038/s41375-020-0776-2.

21. Soverini S, De Benedittis C, Polakova KM, et al. Next-generation sequencing for sensitive detection of BCR-ABL1 mutations relevant to tyrosine kinase inhibitor choice in imatinib-resistant patients. Oncotarget. 2016;7(16):21982-21990. doi:10.18632/ oncotarget. 8010

22. Soverini S, Bavaro L, De Benedittis C, et al. Prospective assessment of NGS-detectable mutations in CML patients with non-optimal response: the NEXT-in-CML study. Blood. 2019;135: 8. doi:10.1182/blood.2019002969

23. Marin D, Ibrahim AR, Lucas C, et al. Assessment of BCR-ABL1 transcript levels at 3 months is the only requirement for predicting outcome for patients with chronic myeloid leukemia treated with tyrosine kinase inhibitors. J Clin Oncol. 2012;30(3):232-238. doi: $10.1200 /$ JCO.2011.38.6565

24. Hjorth-Hansen H, Stenke L, Söderlund S, et al. Dasatinib induces fast and deep responses in newly diagnosed chronic myeloid leukaemia patients in chronic phase: clinical results from a randomised phase-2 study (NordCML006). Eur J Haematol. 2015;94(3):243-250. doi:10.1111/ejh.12423

25. Hochhaus A, Saussele S, Rosti G, et al. Chronic myeloid leukaemia: ESMO clinical practice guidelines for diagnosis, treatment and follow-up†. Ann Oncol. 2017;28(suppl_4):iv41-iv51. doi:10. 1093/annonc/mdx219

26. Branford S, Yeung DT, Parker WT, et al. Prognosis for patients with $\mathrm{CML}$ and $>10 \%$ BCR-ABL1 after 3 months of imatinib depends on the rate of BCR-ABL1 decline. Blood. 2014;124 (4):511-518. doi:10.1182/blood-2014-03-566323

27. Iriyama N, Fujisawa S, Yoshida C, et al. Shorter halving time of BCR-ABL1 transcripts is a novel predictor for achievement of molecular responses in newly diagnosed chronic-phase chronic myeloid leukemia treated with dasatinib: results of the D-first study of Kanto CML study group. Am J Hematol. 2015;90 (4):282-287. doi:10.1002/ajh.23923

28. El Missiry M, Hjorth-Hansen H, Richter J, et al. Early BCR-ABL1 transcript decline after 1 month of tyrosine kinase inhibitor therapy as an indicator for treatment response in chronic myeloid leukemia. Dello Sbarba P, ed. PLoS One. 2017;12(1):e0171041. doi:10.1371/ journal.pone.0171041

29. Hughes TP, Kaeda J, Branford S, et al. Frequency of major molecular responses to imatinib or interferon alfa plus cytarabine in newly diagnosed chronic myeloid leukemia. $N$ Engl J Med. 2003;349(15):1423-1432. doi:10.1056/NEJMoa030513
30. Baccarani M, Castagnetti F, Gugliotta G, Rosti G. A review of the European LeukemiaNet recommendations for the management of CML. Ann Hematol. 2015;94 Suppl 2(S2):S141-7. doi:10.1007/ s00277-015-2322-2

31. Pallera A, Altman JK, Berman E, et al. NCCN guidelines insights: chronic myeloid leukemia, version 1.2017. J Natl Compr Canc Netw. 2016;14(12):1505-1512. doi:10.6004/jnccn.2016.0162

32. Cortes JE, Saglio G, Kantarjian HM, et al. Final 5-year study results of DASISION: the dasatinib versus imatinib study in treatment-naïve chronic myeloid leukemia patients Trial. J Clin Oncol. 2016;34(20):2333-2340. doi:10.1200/JCO.2015.64.8899

33. Hochhaus A, Saglio G, Hughes TP, et al. Long-term benefits and risks of frontline nilotinib vs imatinib for chronic myeloid leukemia in chronic phase: 5-year update of the randomized ENESTnd trial. Leukemia. 2016;30(5):1044-1054. doi:10.1038/leu.2016.5

34. Mahon F-X, Réa D, Guilhot J, et al. Discontinuation of imatinib in patients with chronic myeloid leukaemia who have maintained complete molecular remission for at least 2 years: the prospective, multicentre Stop Imatinib (STIM) trial. Lancet Oncol. 2010;11 (11):1029-1035. doi:10.1016/S1470-2045(10)70233-3

35. Ross DM, Branford S, Seymour JF, et al. Safety and efficacy of imatinib cessation for CML patients with stable undetectable minimal residual disease: results from the TWISTER study. Blood. 2013;122(4):515-522. doi:10.1182/blood-2013-02-483750

36. Hochhaus A, Masszi T, Giles FJ, et al. Treatment-free remission following frontline nilotinib in patients with chronic myeloid leukemia in chronic phase: results from the ENESTfreedom study. Leukemia. 2017;31(7):1525-1531. doi:10.1038/leu.2017.63

37. Imagawa J, Tanaka H, Okada M, et al. Discontinuation of dasatinib in patients with chronic myeloid leukaemia who have maintained deep molecular response for longer than 1 year (DADI trial): a multicentre Phase 2 trial. Lancet Haematol. 2015;2(12):e528e535. doi:10.1016/S2352-3026(15)00196-9

38. Takahashi N, Nishiwaki K, Nakaseko C, et al. Treatment-free remission after two-year consolidation therapy with nilotinib in patients with chronic myeloid leukemia: STAT2 trial in Japan. Haematologica. 2018;103(11):1835-1842. doi:10.3324/haematol.2018.194894

39. Hughes TP, Ross DM. Moving treatment-free remission into mainstream clinical practice in CML. Blood. 2016;128(1):17-23. doi:10.1182/blood-2016-01-694265

40. Breccia M, Foà R. Current information and recommendations on the discontinuation of TKI inhibitors in chronic myeloid leukemia. Curr Oncol Rep. 2018;20(3):23. doi:10.1007/s11912-018-0669-y

41. Rousselot P, Charbonnier A, Cony-Makhoul P, et al. Loss of major molecular response as a trigger for restarting tyrosine kinase inhibitor therapy in patients with chronic-phase chronic myelogenous leukemia who have stopped imatinib after durable undetectable disease. J Clin Oncol. 2014;32(5):424-430. doi:10.1200/JCO.2012.48.5797

42. Rea D, Nicolini FE, Tulliez M, et al. Discontinuation of dasatinib or nilotinib in chronic myeloid leukemia: interim analysis of the STOP 2G-TKI study. Blood. 2017;129(7):846-854. doi:10.1182/ blood-2016-09-742205

43. Cortes J, Rea D, Lipton JH. Treatment-free remission with firstand second-generation tyrosine kinase inhibitors. Am J Hematol. 2019;94(3):346-357. doi:10.1002/ajh.25342

44. Guru Murthy GS, Atallah E. Treatment-free remission in CML: the US perspective. Curr Hematol Malig Rep. 2019;14(1):56-61. doi:10.1007/s11899-019-0496-8

45. Hughes TP, Ross DM. Targeted therapies: remembrance of things past - discontinuation of second-generation TKI therapy for CML. Nat Rev Clin Oncol. 2017;14(4):201-202. doi:10.1038/nrclinonc. 2017.11

46. Bocchia M, Sicuranza A, Abruzzese E, et al. Residual peripheral blood CD26+ leukemic stem cells in chronic myeloid leukemia patients during TKI therapy and during treatment-free remission. Front Oncol. 2018;8:194. doi:10.3389/fonc.2018.00194 
47. Rovida E, Marzi I, Cipolleschi MG, Dello Sbarba P. One more stem cell niche: how the sensitivity of chronic myeloid leukemia cells to imatinib mesylate is modulated within a "hypoxic" environment. Hypoxia (Auckland, NZ). 2014;2:1-10. doi:10.2147/HP.S51812

48. Link-Lenczowska D, Pallisgaard N, Cordua S, et al. A comparison of qPCR and ddPCR used for quantification of the JAK2 V617F allele burden in $\mathrm{Ph}$ negative MPNs. Ann Hematol. 2018;97 (12):2299-2308. doi:10.1007/s00277-018-3451-1

49. Brunetti C, Anelli L, Zagaria A, et al. Droplet digital PCR is a reliable tool for monitoring minimal residual disease in acute promyelocytic leukemia. J Mol Diagn. 2017;19(3):437-444. doi:10.1016/j.jmoldx.2017.01.004

50. Drandi D, Ferrero S, Ladetto M. Droplet digital PCR for minimal residual disease detection in mature lymphoproliferative disorders. Methods Mol Biol. 2018:1768:229-256. doi:10.1007/978-1-49397778-9_14

51. Del Giudice I, Raponi S, Della Starza I, et al. Minimal residual disease in chronic lymphocytic leukemia: a new goal? Front Oncol. 2019;9:689. doi:10.3389/fonc.2019.00689

52. Coccaro N, Anelli L, Zagaria A, et al. Droplet digital PCR is a robust tool for monitoring minimal residual disease in adult philadelphia-positive acute lymphoblastic leukemia. J Mol Diagn. 2018;20(4):474-482. doi:10.1016/j.jmoldx.2018.03.002

53. Hindson CM, Chevillet JR, Briggs HA, et al. Absolute quantification by droplet digital PCR versus analog real-time PCR. Nat Methods. 2013;10(10):1003-1005. doi:10.1038/nmeth.2633

54. Baker M. Digital PCR hits its stride. Nat Methods. 2012;9 (6):541-544. doi:10.1038/nmeth.2027

55. Jennings LJ, George D, Czech J, Yu M, Joseph L. Detection and quantification of BCR-ABL1 fusion transcripts by droplet digital PCR. J Mol Diagn. 2014;16(2):174-179. doi:10.1016/j.jmoldx.20 13.10.007

56. Goh H-G, Lin M, Fukushima T, et al. Sensitive quantitation of minimal residual disease in chronic myeloid leukemia using nanofluidic digital polymerase chain reaction assay. Leuk Lymphoma. 2011;52(5):896-904. doi:10.3109/10428194.2011.555569

57. Franke GN, Maier J, Wildenberger K, et al. Comparison of real-time quantitative PCR and digital droplet PCR for BCR-ABL1 monitoring in patients with chronic myeloid leukemia. J Mol Diagn. 2020;22 (1):81-89. doi:10.1016/j.jmoldx.2019.08.007

58. Maier J, Franke G-N, Schubert K, et al. A comparison of droplet digital PCR and quantitative RT-PCR for low level BCR-ABL in CML patients with molecular responses. Blood. 2014;124 (21):1792. doi:10.1182/blood.v124.21.1792.1792

59. Bernardi S, Malagola M, Zanaglio C, et al. Digital PCR improves the quantitation of DMR and the selection of CML candidates to TKIs discontinuation. Cancer Med. 2019;8(5):2041-2055. doi:10. 1002/cam4.2087

60. Vogelstein B, Kinzler KW. Digital PCR. Proc Natl Acad Sci U S A. 1999;96(16):9236-9241. doi:10.1073/pnas.96.16.9236

61. Sykes PJ, Neoh SH, Brisco MJ, Hughes E, Condon J, Morley AA Quantitation of targets for PCR by use of limiting dilution. Biotechniques. 1992.

62. Whale AS, Huggett JF, Cowen S, et al. Comparison of microfluidic digital PCR and conventional quantitative PCR for measuring copy number variation. Nucleic Acids Res. 2012;40(11):e82. doi:10.10 93/nar/gks203

63. Nicolini FE, Dulucq S, Boureau L, et al. Evaluation of residual disease and TKI duration are critical predictive factors for molecular recurrence after stopping imatinib first-line in chronic phase CML patients. Clin Cancer Res. 2019;25(22):6606-6613. doi:10.11 58/1078-0432.CCR-18-3373

64. Wang WJ, Zheng CF, Liu Z, et al. Droplet digital PCR for BCR/ ABL(P210) detection of chronic myeloid leukemia: a high sensitive method of the minimal residual disease and disease progression. Eur J Haematol. 2018;101(3):291-296. doi:10.1111/ejh.13084
65. Mori S, Vagge E, le Coutre P, et al. Age and dPCR can predict relapse in CML patients who discontinued imatinib: the ISAV study. Am J Hematol. 2015;90(10):910-914. doi:10.1002/ajh.24 120

66. Atallah E, Schiffer CA, Weinfurt KP, et al. Design and rationale for the life after stopping tyrosine kinase inhibitors (LAST) study, a prospective, single-group longitudinal study in patients with chronic myeloid leukemia. BMC Cancer. 2018;18(1):359. doi:10. 1186/s12885-018-4273-1

67. van Ginkel JH, Huibers MMH, van Es RJJ, de Bree R, Willems SM. Droplet digital PCR for detection and quantification of circulating tumor DNA in plasma of head and neck cancer patients. BMC Cancer. 2017;17(1):428. doi:10.1186/s12885-0173424-0

68. Bernardi S, Foroni C, Zanaglio $\mathrm{C}$, et al. Feasibility of tumor-derived exosome enrichment in the onco-hematology leukemic model of chronic myeloid leukemia. Int J Mol Med. 2019;44 (6):2133-2144. doi:10.3892/ijmm.2019.4372

69. Simpson RJ, Jensen SS, Lim JWE. Proteomic profiling of exosomes: current perspectives. Proteomics. 2008;8(19):4083-4099. doi:10.1002/pmic.200800109

70. Zocco D, Ferruzzi P, Cappello F, Kuo WP, Fais S. Extracellular vesicles as shuttles of tumor biomarkers and antitumor drugs. Front Oncol. 2014;4(SEP). doi:10.3389/fonc.2014.00267

71. Sharifi H, Shafiee A, Molavi G, et al. Leukemia-derived exosomes: bringing oncogenic signals to blood cells. $J$ Cell Biochem. 2019;120(10):16307-16315. doi:10.1002/jcb.29018

72. Wojtuszkiewicz A, Schuurhuis GJ, Kessler FL, et al. Exosomes secreted by apoptosis-resistant Acute Myeloid Leukemia (AML) blasts harbor regulatory network proteins potentially involved in antagonism of apoptosis. Mol Cell Proteomics. 2016;15 (4):1281-1298. doi:10.1074/mcp.M115.052944

73. Wang J, De Veirman K, Faict S, et al. Multiple myeloma exosomes establish a favourable bone marrow microenvironment with enhanced angiogenesis and immunosuppression. J Pathol. 2016;23 9(2):162-173. doi:10.1002/path.4712

74. Yeh YY, Ozer HG, Lehman AM, et al. Characterization of CLL exosomes reveals a distinct microRNA signature and enhanced secretion by activation of BCR signaling. Blood. 2015;125 (21):3297-3305. doi:10.1182/blood-2014-12-618470

75. Fu FF, Zhu XJ, Wang HX, et al. BCR-ABL1-positive microvesicles malignantly transform human bone marrow mesenchymal stem cells in vitro. Acta Pharmacol Sin. 2017;38(11):1475-1485. doi:10. 1038/aps.2017.116

76. Cai J, Wu G, Tan X, et al. Transferred BCR/ABL DNA from K562 extracellular vesicles causes chronic myeloid leukemia in immunodeficient mice. Loges S, ed. PLoS One. 2014;9(8):e105200. doi:10. 1371/journal.pone. 0105200

77. Izzo B, Gottardi EM, Errichiello S, Daraio F, Baratè C, Galimberti S. Monitoring chronic myeloid leukemia: how molecular tools may drive therapeutic approaches. Front Oncol. 2019;9. doi:10.3389/fonc.2019.00833.

78. Dufresne SD, Belloni DR, Levy NB, Tsongalis GJ. Quantitative assessment of the BCR-ABL transcript using the cepheid Xpert BCR-ABL monitor assay. Arch Pathol Lab Med. 2007. doi:10.1043/1543-2165(2007)131[947:QAOTBT]2.0.CO;2

79. Enjeti A, Granter N, Ashraf A, et al. A longitudinal evaluation of performance of automated BCR-ABL1 quantitation using cartridge-based detection system. Pathology. 2015;47(6):570-574. doi:10.1097/PAT.0000000000000293

80. Gerrard G, Foong HE, Mudge K, Alikian M, Apperley JF, Foroni L. Cepheid xpert monitor platform for the confirmation of BCR-ABL1 IS conversion factors for the molecular monitoring of chronic myeloid leukaemia. Leuk Res. 2016;49:47-50. doi:10.1016/ j.leukres.2016.08.007 
81. López-Jorge CE, Gómez-Casares MT, Jiménez-Velasco A, et al. Comparative study of BCR-ABL1 quantification: xpert assay, a feasible solution to standardization concerns. Ann Hematol. 2012;91(8):1245-1250. doi:10.1007/s00277-012-1468-4

82. García-Gutiérrez V, Gómez-Casares MT, Puerta JM, et al. A BCR-ABL1 cutoff of $1.5 \%$ at 3 months, determined by the GeneXpert system, predicts an optimal response in patients with chronic myeloid leukemia. Speletas M, ed. PLoS One. 2017;12(3): e0173532. doi:10.1371/journal.pone.0173532

83. O'Dwyer ME, Swords R, Nagler A, et al. Nilotinib 300mg BID as frontline treatment of CML: prospective analysis of the Xpert BCR-ABL Monitor system and significance of 3-month molecular response. Leuk Res. 2014;38(3):310-315. doi:10.1016/j.leukres.20 13.11.016

84. Day G-J, Lockwood C, Payton JE, et al. Development of Xpert ${ }^{\circledR}$ BCR-ABL ultra, an automated and standardized multiplex assay with required performance characteristics for BCR-ABL1 quantitative measurement on an international reporting scale. Blood. 2015;126(23):2793. doi:10.1182/blood.v126.23.2793.2793

85. Sharplin K, Altamura H, Taylor K, Wellwood J, Taylor D, Branford S. Chronic myeloid leukaemia: the dangers of not knowing your BCR-ABL1 transcript. Leuk Res. 2019;87:106231. doi:10.1016/j.leukres.2019.106231

86. Torra OS, Beppu L, Smith JL, et al. Paper or plastic? BCR-ABL1 quantitation and mutation detection from dried blood spots. Blood. 2016;127(22):2773-2774. doi:10.1182/blood-2015-12-689059

87. Avelino KYPS, Frias IAM, Lucena-Silva N, et al. Attomolar electrochemical detection of the BCR/ABL fusion gene based on an amplifying self-signal metal nanoparticle-conducting polymer hybrid composite. Colloids Surf B Biointerfaces. 2016;148:57 6-584. doi:10.1016/j.colsurfb.2016.09.029

88. Chen J, Zhang J, Wang $\mathrm{K}$, Lin $\mathrm{X}$, Huang $\mathrm{L}$, Chen $\mathrm{G}$. Electrochemical biosensor for detection of $\mathrm{BCR} / \mathrm{ABL}$ fusion gene using locked nucleic acids on 4-aminobenzenesulfonic acid-modified glassy carbon electrode. Anal Chem. 2008;80(21):8028-8034. doi:10.1021/ac801040e

89. Ensafi AA, Taei M, Rahmani HR, Khayamian T. Sensitive DNA impedance biosensor for detection of cancer, chronic lymphocytic leukemia, based on gold nanoparticles/gold modified electrode. Electrochim Acta. 2011;56(24):8176-8183. doi:10.1016/j.electacta.2011.05.124

90. Zagaria A, Anelli L, Coccaro N, et al. BCR-ABL1 e6a2 transcript in chronic myeloid leukemia: biological features and molecular monitoring by droplet digital PCR. Virchows Arch. 2015;467 (3):357-363. doi:10.1007/s00428-015-1802-z

91. Qin YZ, Jiang Q, Jiang $H$, et al. Prevalence and outcomes of uncommon BCR-ABL1 fusion transcripts in patients with chronic myeloid leukaemia: data from a single centre. $\mathrm{Br} J$ Haematol. 2018;182(5):693-700. doi:10.1111/bjh.15453

92. Duan MH, Li H, Cai H. A rare e13a3 (b2a3) BCR-ABL1 fusion transcript with normal karyotype in chronic myeloid leukemia: the challenges in diagnosis and monitoring minimal residual disease (MRD). Leuk Res. 2017;59:8-11. doi:10.1016/j.leukres.2017.05.009

93. Tong YQ, Zhao ZJ, Liu B, et al. New rapid method to detect BCR-ABL fusion genes with multiplex RT-qPCR in one-tube at a time. Leuk Res. 2018;69:47-53. doi:10.1016/j.leukres.2018.04.001

94. Burmeister T, Reinhardt R. A multiplex PCR for improved detection of typical and atypical BCR-ABL fusion transcripts. Leuk Res. 2008;32(4):579-585. doi:10.1016/j.leukres.2007.08.017

95. Link-Lenczowska D, Sacha T, Zawada M, Czekalska S, Florek I, Skotnicki AB. Nietypowe odmiany transkryptu BCR-ABLu chorych na przewlekłą białaczkę szpikową- schemat postępowania diagnostycznego w monitorowaniu minimalnej choroby resztkowej [Atypical BCR-ABL transcripts in patients with chronic myeloid leukemia-the scheme for the diagnosis and monitoring of minimal residual disease]. Przegl Lek. 2014;71(5):258-262. Polish.
96. Yuda J, Miyamoto T, Odawara J, et al. Persistent detection of alternatively spliced BCR-ABL variant results in a failure to achieve deep molecular response. Cancer Sci. 2017;108(11):22 04-2212. doi:10.1111/cas. 13353

97. Ross DM, Branford S, Seymour JF, et al. Patients with chronic myeloid leukemia who maintain a complete molecular response after stopping imatinib treatment have evidence of persistent leukemia by DNA PCR. Leukemia. 2010;24(10):1719-1724. doi:10. 1038/leu.2010.185

98. Waller CF, Dennebaum G, Feldmann C, Lange W. Long-template DNA polymerase chain reaction for the detection of the bcr/abl translocation in patients with chronic myelogenous leukemia. Clin Cancer Res. 1999;5(12):4146-4151.

99. Mattarucchi E, Guerini V, Rambaldi A, et al. Microhomologies and interspersed repeat elements at genomic breakpoints in chronic myeloid leukemia. Genes Chromosom Cancer. 2008;47(7):625-63 2. doi:10.1002/gcc. 20568

100. Siebert PD, Chenchik A, Kellogg DE, Lukyanov KA, Lukyanov SA. An improved PCR method for walking in uncloned genomic DNA. Nucleic Acids Res. 1995;23(6):1087-1088. doi:10.1093/nar/23.6.1087

101. Mattarucchi E, Spinelli O, Rambaldi A, et al. Molecular monitoring of residual disease in chronic myeloid leukemia by genomic DNA compared with conventional mRNA analysis. J Mol Diagn. 2009;11(5):482-487. doi:10.2353/jmoldx.2009.080150

102. Pagani IS, Spinelli O, Mattarucchi E, et al. Genomic quantitative real-time PCR proves residual disease positivity in more than $30 \%$ samples with negative mRNA-based qRT-PCR in chronic myeloid leukemia. Oncoscience. 2014;1(7):510-521. doi:10.1863 2/oncoscience.65

103. Bartley PA, Martin-Harris MH, Budgen BJ, Ross DM, Morley AA. Rapid isolation of translocation breakpoints in chronic myeloid and acute promyelocytic leukaemia: research paper. $\mathrm{Br} J$ Haematol. 2010;149(2):231-236. doi:10.1111/j.1365-2141.2009.08071.x

104. Bartley PA, Ross DM, Latham S, et al. Sensitive detection and quantification of minimal residual disease in chronic myeloid leukaemia using nested quantitative PCR for BCR-ABL DNA. Int $J$ Lab Hematol. 2010;32(6PART 1):222-228. doi:10.1111/ j.1751-553X.2010.01236.X

105. Bartley PA, Latham S, Budgen B, et al. A DNA real-time quantitative PCR method suitable for routine monitoring of low levels of minimal residual disease in chronic myeloid leukemia. $J \mathrm{Mol}$ Diagn. 2015;17(2):185-192. doi:10.1016/j.jmoldx.2014.10.002

106. Pagani IS, Dang P, Kommers IO, et al. BCR-ABL1 genomic DNA PCR response kinetics during first-line imatinib treatment of chronic myeloid leukemia. Haematologica. 2018;103(12):20 26-2032. doi:10.3324/haematol.2018.189787

107. Cumbo C, Impera L, Minervini CF, et al. Genomic BCR-ABL1 breakpoint characterization by a multistrategy approach for "personalized monitoring" of residual disease in chronic myeloid leukemia patients. Oncotarget. 2018;9(13):10978-10986. doi:10.18632/ oncotarget.23971

108. Score J, Calasanz MJ, Ottman O, et al. Analysis of genomic breakpoints in p190 and p210 BCR-ABL indicate distinct mechanisms of formation. Leukemia. 2010;24(10):1742-1750. doi:10.1038/leu.2010.174

109. Krumbholz M, Karl M, Tauer JT, et al. Genomic BCR-ABL1 breakpoints in pediatric chronic myeloid leukemia. Genes Chromosom Cancer. 2012;51(11):1045-1053. doi:10.1002/gcc.21989

110. Krumbholz M, Goerlitz K, Albert C, Lawlor J, Suttorp M, Metzler M. Large amplicon droplet digital PCR for DNA-based monitoring of pediatric chronic myeloid leukaemia. J Cell Mol Med. 2019;23(8):4955-4961. doi:10.1111/jcmm.14321

111. Linhartova J, Hovorkova L, Soverini S, et al. Characterization of 46 patient-specific BCR-ABL1 fusions and detection of SNPs upstream and downstream the breakpoints in chronic myeloid leukemia using next generation sequencing. Mol Cancer. 2015;14 (1):1-5. doi:10.1186/s12943-015-0363-8 
112. Alikian $M$, Ellery $P$, Forbes $M$, et al. Next-generation sequencing-assisted DNA-based digital PCR for a personalized approach to the detection and quantification of residual disease in chronic myeloid leukemia patients. J Mol Diagn. 2016;18 (2):176-189. doi:10.1016/j.jmoldx.2015.09.005

113. Prieto-Conde MI, Corchete LA, García-Álvarez M, et al. A new next-generation sequencing strategy for the simultaneous analysis of mutations and chromosomal rearrangements at DNA level in acute myeloid leukemia patients. J Mol Diagn. 2020;22(1):60-71. doi:10.1016/j.jmoldx.2019.08.002

114. Minervini CF, Cumbo C, Orsini P, et al. Nanopore sequencing in blood diseases: a wide range of opportunities. Front Genet 2020;11(February):76. doi:10.3389/fgene.2020.00076

115. Minervini CF, Cumbo C, Orsini P, et al. TP53 gene mutation analysis in chronic lymphocytic leukemia by nanopore MinION sequencing. Diagn Pathol. 2016;11(1):1-9. doi:10.1186/s13000-016-0550-y

116. Minervini CF, Cumbo $C$, Orsini $P$, et al. Mutational analysis in BCR-ABL1 positive leukemia by deep sequencing based on nanopore MinION technology. Exp Mol Pathol. 2017;103(1):33-37. doi:10.1016/j.yexmp.2017.06.007

117. Orsini P, Minervini CF, Cumbo C, et al. Design and MinION testing of a nanopore targeted gene sequencing panel for chronic lymphocytic leukemia. Sci Rep. 2018;8(1):1-10. doi:10.1038/s41598-018-30330-y

118. Cumbo C, Minervini CF, Orsini P, et al. Nanopore targeted sequencing for rapid gene mutations detection in acute myeloid leukemia. Genes 2019. 2019;10(12):1026. doi:10.3390/GENES10121026

119. Radich J. Is DNA a better assay for residual disease in chronic myeloid leukemia? Haematologica. 2018;103(12):1942-1944. doi:10.3324/haematol.2018.205583

120. Rea D, Mahon FX. How I manage relapse of chronic myeloid leukaemia after stopping tyrosine kinase inhibitor therapy. $\mathrm{Br}$ J Haematol. 2018;180(1):24-32. doi:10.1111/bjh.14973

121. Weerkamp F, Dekking E, Ng YY, et al. Flow cytometric immunobead assay for the detection of BCR-ABL fusion proteins in leukemia patients. Leukemia. 2009;23(6):1106-1117. doi:10.1038/leu.2009.93

122. Raponi S, De Propris MS, Wai H, et al. An accurate and rapid flow cytometric diagnosis of BCR-ABL positive acute lymphoblastic leukemia. Haematologica. 2009;94(12):1767-1770. doi:10.3324/ haematol.2009.010900

123. Yujie W, Yu Z, Sixuan Q, et al. Detection of BCR-ABL fusion proteins in patients with leukemia using a cytometric bead array. Leuk Lymphoma. 2012;53(3):451-455. doi:10.3109/10428194.2011.625100

124. Löf L, Arngården L, Olsson-Strömberg U, et al. Flow cytometric measurement of blood cells with BCR-ABL1 fusion protein in chronic myeloid leukemia. Sci Rep. 2017;7(1):1-9. doi:10.1038/s41598-01700755-y

125. Shi M, Dong X, Huo L, Wei X, Wang F, Sun K. The potential roles and advantages of single cell sequencing in the diagnosis and treatment of hematological malignancies.Adv Exp Med Biol. 2018:1068:119-133. doi:10.1007/978-981-13-0502-3_10

126. Giustacchini A, Thongjuea S, Barkas N, et al. Single-cell transcriptomics uncovers distinct molecular signatures of stem cells in chronic myeloid leukemia. Nat Med. 2017;23(6):692-702. doi: $10.1038 / \mathrm{nm} .4336$
127. Warfvinge R, Geironson L, Sommarin MNE, et al. Single-cell molecular analysis defines therapy response and immunophenotype of stem cell subpopulations in CML. Blood. 2017;129 (17):2384-2394. doi:10.1182/blood-2016-07-728873

128. Pieri L, Spolverini A, Scappini B, et al. Concomitant occurrence of BCR-ABL and JAK2V617F mutation. Blood. 2011;118(12):34 45-3446. doi:10.1182/blood-2011-07-365007

129. Albano F, Anelli L, Zagaria A, et al. Decreased TET2 gene expression during chronic myeloid leukemia progression. Leuk Res. 2011;35:11. doi:10.1016/j.leukres.2011.07.013

130. Herrmann H, Sadovnik I, Cerny-Reiterer S, et al. Dipeptidylpeptidase IV (CD26) defines leukemic stem cells (LSC) in chronic myeloid leukemia. Blood. 2014;123 (25):3951-3962. doi:10.1182/blood-2013-10-536078

131. Valent P, Sadovnik I, Ráčil Z, et al. DPPIV (CD26) as a novel stem cell marker in $\mathrm{Ph}+$ chronic myeloid leukaemia. Eur J Clin Invest. 2014;44(12):1239-1245. doi:10.1111/eci.12368

132. Culen M, Borsky M, Nemethova V, et al. Quantitative assessment of the CD26+ leukemic stem cell compartment in chronic myeloid leukemia: patient-subgroups, prognostic impact, and technical aspects. Oncotarget. 2016;7(22):33016-33024. doi:10.18632/oncotarget.9108

133. Galimberti S, Grassi S, Barate C, et al. The polycomb BMI1 protein is co-expressed with $\mathrm{CD} 26+$ in leukemic stem cells of chronic myeloid leukemia. Front Oncol. 2018;8(DEC). doi:10.3389/fonc.2018.00555

134. Rizo A, Horton SJ, Olthof S, et al. BMI1 collaborates with BCR-ABL in leukemic transformation of human CD34 + cells. Blood. 2010;116 (22):4621-4630. doi:10.1182/blood-2010-02-270660

135. Mourgues L, Imbert V, Nebout M, et al. The BMI1 polycomb protein represses cyclin G2-induced autophagy to support proliferation in chronic myeloid leukemia cells. Leukemia. 2015;29 (10):1993-2002. doi:10.1038/leu.2015.112

136. Ohyashiki JH, Ohtsuki K, Mizoguchi I, et al. Downregulated microRNA-148b in circulating PBMCs in chronic myeloid leukemia patients with undetectable minimal residual disease: A possible biomarker to discontinue imatinib safely. Drug Des Devel Ther. 2014;8:1151-1159. doi:10.2147/DDDT.S66812

137. Ohyashiki K, Umezu T, Katagiri S, et al. Downregulation of plasma miR-215 in chronic myeloid leukemia patients with successful discontinuation of imatinib. Int J Mol Sci. 2016;17(4):1-11. doi:10.3390/ijms 17040570

138. Pagani IS, Kok CH, Saunders VA, et al. A method for next-generation sequencing of paired diagnostic and remission samples to detect mitochondrial DNA mutations associated with leukemia. J Mol Diagn. 2017;19(5):711-721. doi:10.1016/j.jmoldx.2017.05.009

139. Chomel JC, Bonnet ML, Sorel N, et al. Leukemic stem cell persistence in chronic myeloid leukemia patients with sustained undetectable molecular residual disease. Blood. 2011;118(13):36 57-3660. doi:10.1182/blood-2011-02-335497

140. Nair RR, Tolentino J, Hazlehurst LA. The bone marrow microenvironment as a sanctuary for minimal residual disease in CML. Biochem Pharmacol. 2010;80(5):602-612. doi:10.1016/j.bcp.2010. 04.003
Cancer Management and Research is an international, peer-reviewed open access journal focusing on cancer research and the optimal use of preventative and integrated treatment interventions to achieve improved outcomes, enhanced survival and quality of life for the cancer patient.
The manuscript management system is completely online and includes a very quick and fair peer-review system, which is all easy to use. Visit http://www.dovepress.com/testimonials.php to read real quotes from published authors. 